\title{
Cognitive Flexibility is Associated with KIBRA Variant and Modulated by Recent Tobacco Use
}

\author{
Huiping Zhang ${ }^{1,2}$, Henry R Kranzler ${ }^{3,4}$, James Poling ${ }^{1,2}$, Jeffrey R Gruen ${ }^{5,6}$ and Joel Gelernter*, 1,2,6,7 \\ 'Division of Human Genetics, Department of Psychiatry, Yale University School of Medicine, New Haven, CT, USA; ${ }^{2}$ VA Connecticut Healthcare \\ System, West Haven, CT, USA; ${ }^{3}$ Department of Psychiatry, University of Connecticut School of Medicine, Farmington, CT, USA; ${ }^{4}$ Department of \\ Genetics and Developmental Biology, University of Connecticut School of Medicine, Farmington, CT, USA; ${ }^{5}$ Department of Pediatrics, Yale \\ University School of Medicine, New Haven, CT, USA; ${ }^{\circ}$ Department of Genetics, Yale University School of Medicine, New Haven, CT, USA; \\ ${ }^{7}$ Department of Neurobiology, Yale University School of Medicine, New Haven, CT, USA
}

\begin{abstract}
The kidney and brain expressed protein gene (KIBRA) and the calsyntenin 2 gene (CLSTN2) are reportedly involved in synaptic plasticity. Single nucleotide polymorphisms (SNPs) rs I 7070I45 (KIBRA) and rs6439886 (CLSTN2) have been found to affect memory performance measures. This study examined the association of KIBRA SNP rs/7070I45 and CLSTN2 SNPs rs6439886 and rs/7348572 (a nonsynonymous variant) with cognitive flexibility in 674 African Americans (AAs; 526 current smokers) and 419 European Americans (EAs; 318 current smokers). The subjects' cognitive flexibility was assessed using the Wisconsin Card Sorting Test. The effects on cognitive flexibility of sex, age, education, and tobacco recency (a possible mediator of gene effects in smokers), the three SNPs, and the interaction of each SNP with tobacco recency were analyzed using multivariate analysis of variance. In AAs, there were no main or interaction effects of the SNPs on cognitive flexibility. In EAs, the two CLSTN2 SNPs showed no main effect on cognitive flexibility. However, among EAs, individuals with the KIBRA rs I7070 I $45 \mathrm{~T}$ allele made significantly more perseverative responses $(P=0.002)$ and perseverative errors $(P=0.002)$ than those with no $T$ allele. Furthermore, among EAs with the rs 17070 I $45 \mathrm{~T}$ allele, current smokers made significantly fewer perseverative responses $(P<0.00 \mathrm{I})$ and perseverative errors $(P<0.00 \mathrm{I})$ than past smokers. Nongenetic factors (age, education, and tobacco recency) had substantial effects on cognitive flexibility in both AAs and EAs. We conclude that variation in KIBRA influences cognitive flexibility in a population-specific way, and that current smoking status moderates this effect.
\end{abstract}

Neuropsychopharmacology (2009) 34, 2508-25 I6; doi:I0.1038/npp.2009.80; published online I5 July 2009

Keywords: KIBRA; CLSTN2; cognitive flexibility; Wisconsin Card Sorting Test; single nucleotide polymorphism, SNP $\times$ tobacco recency

\section{INTRODUCTION}

Cognition is a set of high-level brain functions that vary substantially among individuals. The variability of cognition is largely attributable to genetic influence. Twin studies have demonstrated that the heritability is about $60 \%$ for general cognitive ability and about $50 \%$ for memory (McClearn et al, 1997). Moreover, heritability for working memory was estimated to be 33-64\% (Ando et al, 2001; Wright et al, 2001; Chen et al, 2009) and heritability for episodic memory was shown to vary from 0 to $57 \%$ (Johansson et al, 1999; Taylor, 2007; Chen et al, 2009). Twin studies also indicated a high heritability (above 60\%) for attention problems (Polderman et al, 2006). As cognition is a complex trait, it may also be modulated by environment and gene-environment interaction.

*Correspondence: Dr J Gelernter, Department of Psychiatry, Yale University School of Medicine, VA Connecticut Healthcare System, Psychiatry 116A2, 950 Campbell Avenue, West Haven, CT 065।6, USA, Tel.: + 203932 57llext. 3599, Fax: + 203937 474l, E-mail: joel.gelernter@yale.edu

Received 7 April 2009; revised 9 June 2009; accepted I5 June 2009
Genes involved in synaptic signaling or plasticity have been implicated in cognitive variability. Recently, two genes have received particular attention for these effects. One is the WW and $\mathrm{C} 2$ domain containing 1 gene (WWClor KIBRA) on chromosome 5q34-q35.2 and the other is the calsyntenin 2 gene (CLSTN2) on chromosome 3q23. KIBRA encodes the kidney and brain expressed protein (or KIBRA), which is highly expressed in the kidney and liver (Kremerskothen et al, 2003). As a postsynaptic scaffold protein connecting cytoskeletal and signaling molecule, KIBRA is also found in memory-related brain structures including the hippocampus and the temporal lobe (Johannsen et al, 2008; Yoshihama et al, 2009). KIBRA may function in memory performance through interaction with protein kinase Mzeta (PKM $\zeta)$, which participates in synaptic plasticity and memory storage (Buther et al, 2004; Pastalkova et al, 2006; Shema et al, 2007). KIBRA and PKM $\zeta$ colocalize in brain regions such as the hippocampal CA1, $\mathrm{CA} 2$, and the dentate gyrus (key regions for memory functions; Yoshihama et al, 2009). CLSTN2 encodes the synaptic protein calsyntenin 2 or CLSTN2. This protein appears exclusively in the brain, with high levels in cortical 
gamma-aminobutyric acid (GABA)ergic interneurons and in medial temporal lobe regions (Hintsch et al, 2002).

Variation in KIBRA and CLSTN2 may covary with cognitive performance. Papassotiropoulos et al (2006) found that carriers of the KIBRA (rs17070145) $\mathrm{T}$ allele or the CLSTN2 (rs6439886) $\mathrm{T}$ allele performed better on multiple episodic memory tasks than those homozygous for the C allele at either rs17070145 or rs6439886. Furthermore, using functional magnetic resonance imaging, they observed that hippocampal activation was significantly greater in KIBRA (rs17070145) $\mathrm{T}$ allele noncarriers than in $\mathrm{T}$ allele carriers during an episodic memory task. This implied that $\mathrm{T}$ allele noncarriers had poorer memory ability, requiring that their hippocampi had to work harder to accomplish the same memory task. Based on these findings, several other studies further examined the role of KIBRA and CLSTN2 in cognitive function. Almeida et al (2008) also noticed that KIBRA SNP rs17070145 was associated with episodic memory. Schaper et al (2008) found that the influence of KIBRA SNP rs17070145 was restricted to hippocampal-related episodic memory. Nevertheless, inconsistent results have been reported as well. Nacmias et al (2008) found that individuals with the KIBRA (rs17070145) $\mathrm{T}$ allele performed more poorly on long-term memory tests than individuals with no T allele. Need et al (2008) found no association between SNP rs17070145 and multiple verbal memory tasks.

As memory impairment is a major component of Alzheimer's disease (AD), KIBRA variants were hypothesized to confer susceptibility to the development of $A D$. One study showed that the KIBRA (rs17070145) C allele was significantly associated with late-onset $\mathrm{AD}$ (Corneveaux et al, 2008). However, another study showed that the KIBRA (rs17070145) $\mathrm{T}$ allele was associated with an increased risk for very-late-onset AD (Rodriguez-Rodriguez et al, 2009). Compared to KIBRA, the association of CLSTN2 variants and $A D$ is less well studied. In addition to the findings of Papassotiropoulos et al (2006) mentioned above, Jacobsen et al (2009) reported that CLSTN2 SNP rs6439886 had a significant main or interactive effect with prenatal or adolescent exposure to smoking on verbal or visuospatial memory. Moreover, Uhl et al (2008) reported that variation in CLSTN2 was associated with smokers' ability to achieve and sustain abstinence from smoking.

As the relationship between KIBRA or CLSTN2 and cognitive function is not clear, we examined whether variation in KIBRA or CLSTN2 affects cognitive flexibility. Additionally, cognitive flexibility may be affected by tobacco use. There is evidence that nicotine administration can produce short-term enhancement of attention and memory (Maggio et al, 1998; Ernst et al, 2001) and smoking cessations can lead to acute impairment of verbal and working memory (Jacobsen et al, 2005). Therefore, we also analyzed the effect of smoking and gene-smoking interaction on cognitive flexibility.

\section{MATERIALS AND METHODS}

\section{Subjects}

A total of 674 unrelated African Americans (AAs) and 419 unrelated European Americans (EAs) - originally recruited
Table I Characteristics of Study Subjects and Recency of Tobacco Use

\begin{tabular}{lcc}
\hline & $\begin{array}{c}\text { African } \\
\text { Americans }\end{array}$ & $\begin{array}{c}\text { European } \\
\text { Americans }\end{array}$ \\
\hline Number of subjects & 674 & 419 \\
Males (\%) & $354(52.5 \%)$ & $248(59.2 \%)$ \\
Age (years \pm SD) & $41( \pm 10)$ & $40( \pm 12)$ \\
Education (years \pm SD) & $12( \pm 3)$ & $13( \pm 3)$ \\
Recency of Tobacco Use & & \\
I $\leqslant 2$ weeks (current user) & $526(78.0 \%)$ & $318(75.9 \%)$ \\
$2 \quad 2-4$ weeks & $4(0.6 \%)$ & $4(0.9 \%)$ \\
$3 \quad$ I month-6 months & $6(0.9 \%)$ & $9(2.1 \%)$ \\
$4 \quad 6$ months-I year & $10(1.5 \%)$ & $1(0.2 \%)$ \\
$5 \quad>$ I year & $128(19.0 \%)$ & $87(20.8 \%)$ \\
Nicotine dependence $(\%)$ & & $260(62.0 \%)$ \\
\hline
\end{tabular}

for genetic association studies of drug or alcohol dependence (Zhang et al, 2009) - participated in this study. They were interviewed using an electronic version of the SemiStructured Assessment for Drug Dependence and Alcoholism (SSADDA) instrument (Pierucci-Lagha et al, 2005; Pierucci-Lagha et al, 2007). Information on sex, age, years of education, and the recency of tobacco use was collected at the baseline interview. All 674 AAs and 419 EAs reported a lifetime history of tobacco use, which was quantitated as a tobacco recency score (1: last smoked within 2 weeks; 2 : last smoked in the past 2-4 weeks; 3 : last smoked in the past 1-6 months; 4: last smoked in the past 6-12 months; 5: last smoked over 1 year ago). The majority of AAs $(526 ; 78.0 \%)$ were current tobacco users (based on last tobacco use $\leqslant 2$ weeks), and among them, 404 had a lifetime DSM-IV (American Psychiatric Association, 1994) diagnosis of nicotine dependence (ND). A similar proportion of EAs $(318 ; 75.9 \%)$ were current tobacco users, and among them, 260 had a lifetime DSM-IV diagnosis of ND. Subjects affected with major psychotic disorders (ie, schizophrenia, schizoaffective disorder, or bipolar disorder I) were excluded. Characteristics of the participants in this study are presented in Table 1. They were recruited at the University of Connecticut Health Center (Farmington, CT, USA) or the Yale University School of Medicine (APT Foundation, New Haven, CT, USA). The study protocol was approved by the institutional review board at each institution, and a certificate of confidentiality for the work was obtained from NIH (NIDA). Before study participation, all subjects provided written informed consent after receiving a complete description of the study.

\section{WCST Assessment of Cognitive Flexibility}

Cognitive flexibility is the human ability to adapt one's cognitive processing strategies to face new and unexpected conditions in the environment (Canas et al, 2003). It is characterized by learning, memory, set shifting, etc. To evaluate whether cognitive flexibility is influenced by 
specific genetic factors and/or tobacco use, we used the 128-card computerized version of the Wisconsin Card Sorting Test (WCST; Heaton et al, 1999). The WCST is a complex test that involves multiple cognitive processes (eg, problem solving, set shifting, working memory, and attention). During the test, subjects were required to match response cards to four stimulus cards on three dimensions (color, form, or number) by pressing one of four number keys (1-4) on the computer keyboard. The participant was required to determine which sorting principle was correct and when the principle would shift during the test. The computerized version of the WCST continues until all 128 cards are sorted, which differs from the traditional WCST in which the test ends after six correct categories are completed (Robinson et al, 1980).

In this study, three indices of the WCST were used to assess each individual's cognitive flexibility: percentage of perseverative responses (\%PR), percentage of perseverative errors (\%PE), and percentage of nonperseverative errors $(\% \mathrm{~N}-\mathrm{PE})$. Factor analysis of the WCST has shown that perseverative errors could be the most useful outcome measure in assessing executive function (Greve et al., 2005). Higher values of $\% \mathrm{PR}, \% \mathrm{PE}$, and/or $\% \mathrm{~N}-\mathrm{PE}$ are indicative of poorer WCST performance and less cognitive flexibility.

\section{DNA Sample and SNP Genotyping}

In most cases, DNA was obtained from immortalized lymphoblastoma cell lines, but for a small number of subjects, DNA was obtained directly from blood or saliva. In addition to the two SNPs that have been studied previously (ie, rs17070145 in KIBRA intron 9 and rs6439886 in CLSTN2 intron 1), we examined a rare nonsynonymous variant (rs17348572, $\mathrm{Thr}(\mathrm{C}) / \mathrm{Ile}(\mathrm{T})$ ) in CLSTN2 exon 7. SNPs were genotyped with a fluorogenic $5^{\prime}$ nuclease assay (TaqMan) method (Shi et al, 1999), using the ABI PRISM 7900HT Sequence Detection System (ABI, Foster City, CA, USA).

\section{Statistical Analysis}

The main effect of the three gene variants and their interactive effects with recent tobacco use on cognitive flexibility were analyzed in AAs and EAs separately. A multivariate analysis of variance was performed using the general linear model (GLM) procedure in the SPSS16.0 software package (SPSS Inc., Chicago, Illinois). WCST indices (\%PR, \%PE, and \%N-PE) were treated as dependent variables, SNP genotypes as independent variables, and nongenetic factors (sex, age, tobacco recency, and years of education) as covariates. Interactive effects of genotypes and tobacco recency on cognitive flexibility were examined as well. Bonferroni corrections were used to avoid inflating type 1 error due to multiple testing. The influence of continuous variables (age and years of education) on cognitive flexibility was analyzed by correlational analyses in SPSS 16.0.

\section{RESULTS}

The influence of nongenetic factors on cognitive flexibility as measured by the three WCST indices (\%PR, \%PE, and $\% \mathrm{~N}-\mathrm{PE}$ ) is presented in Tables 2 and 3. Age was strongly inversely correlated with cognitive flexibility (including working memory and set shifting) in both AAs and EAs, such that older individuals made more perseverative responses (AAs: $r=0.235, P<0.001$; EAs: $r=0.200$, $P<0.001$ ), perseverative errors (AAs: $r=0.245, P<0.001$; EAs: $r=0.210, P<0.001)$, and nonperseverative errors (AAs: $r=0.135, P<0.001$; EAs: $r=0.190, P<0.001$ ). Years of education were directly correlated with cognitive flexibility in both AAs (\%PR: $r=-0.114, P=0.003$; \%PE: $r=-0.123, P=0.001 ; \% \mathrm{~N}-\mathrm{PE}: r=-0.164, P<0.001)$ and EAs (\%PR: $r=-0.094, \quad P=0.054 ; \quad \% \mathrm{PE}: \quad r=-0.096$, $P=0.056 ; \% \mathrm{~N}-\mathrm{PE}: r=-0.092, P=0.061)$, but the effect of education on cognitive flexibility was stronger in AAs. Welleducated subjects made fewer perseverative responses, perseverative errors, and nonperseverative errors. Recent tobacco use was associated with poorer performance on two WCST domains (ie, significantly greater perseverative responses and perseverative errors) in AAs (\%PR: $\left.\mathrm{F}_{(1,673)}=7.70, P=0.006 ; \% \mathrm{PE}: \mathrm{F}_{(1,673)}=6.94, P=0.008\right)$. In contrast, recent tobacco use was associated with slightly better performance on two WCST domains (ie, fewer perseverative responses and perseverative errors) in EAs (\%PR: $\quad \mathrm{F}_{(1,418)}=3.72, \quad P=0.055 ; \quad \% \mathrm{PE}: \quad \mathrm{F}_{(1,418)}=2.26$, $P=0.133$ ). Other nongenetic factors (sex and nicotine dependence) did not show a significant effect on cognitive flexibility in either AAs or EAs.

There were no significant main effects of the three SNPs (KIBRA SNP rs17070145 and CLSTN2 SNPs rs6439886 and rs17348572; Table 4) or interactions of the SNPs with recent tobacco use (data not shown) on cognitive flexibility in AAs. However, in EAs, SNP rs17070145 (KIBRA) significantly influenced two domains of cognitive flexibility (\%PR: $\left.\mathrm{F}_{(2,412)}=5.14, \quad P=0.006 ; \% \mathrm{PE}: \mathrm{F}_{(2,412)}=5.09, \quad P=0.006\right)$. Carriers of the rs $17070145 \mathrm{~T}$ allele made significantly more perseverative responses $\left(\mathrm{F}_{(1,412)}=9.75, P=0.002\right)$ and perseverative errors $\left(\mathrm{F}_{(1,412)}=9.78, P=0.002\right)$ than those homozygous for the $\mathrm{C}$ allele (Table 5). These significant $P$ values can withstand Bonferroni correction (at the level of $\alpha=0.05 /(3 * 3)=0.006$, with three SNPs tested for their effect on three WCST domains). Nonperseverative errors (one of the three WCST domains examined in this study) were not significantly affected by SNP rs17070145 in EAs.

To determine whether recent tobacco use moderates the genetic effect of SNP rs17070145 in EAs, we examined the interaction of this SNP with recent tobacco use. As shown in Figure 1a, EA subjects with the rs17070145 $\mathrm{T}$ allele (genotypes CT and TT) who were current smokers had markedly better performance than past smokers on two WCST measures (\%PR: $\mathrm{F}_{(1,206)}=25.03, P<0.001$; \%PE: $\left.\mathrm{F}_{(1,206)}=23.41, P<0.001\right)$. In EA subjects homozygous for the rs17070145 C allele (genotype: CC), cognitive flexibility did not differ as a function of current tobacco use (Figure 1b). As in AA subjects, the two CLSTN2 SNPs (rs6439886 and rs17348572) showed neither a main effect (Table 5) nor an interactive effect with current tobacco use on cognitive flexibility (data not shown).

\section{DISCUSSION}

Human cognition is a polygenic trait. Genes participating in synaptic signaling or plasticity in brain regions such as the 
Table 2 Influence of Nongenetic Factors on Cognitive Flexibility Measured by Wisconsin Card Sorting Tests in African Americans (AAs)

\begin{tabular}{|c|c|c|c|c|}
\hline & & \%PR & \%PE & $\% \mathbf{N}-\mathbf{P E}$ \\
\hline \multicolumn{5}{|c|}{ Effects of continuous nongenetic variables (correlation analyses) } \\
\hline Age & & $P<0.001$ & $P<0.001$ & $P<0.001$ \\
\hline \multirow[t]{3}{*}{ Education } & & $P=0.003$ & $P=0.001$ & $P<0.001$ \\
\hline & n & \%PR & \%PE & $\%$ N-PE \\
\hline & & (mean \pm SEM) & (mean \pm SEM) & (mean \pm SEM) \\
\hline \multicolumn{5}{|c|}{ Effects of categorical nongenetic variables (multivariate GLM procedure) } \\
\hline \multicolumn{5}{|l|}{ Sex } \\
\hline \multicolumn{5}{|c|}{ Tobacco recency ${ }^{\mathrm{a}}$} \\
\hline$\leqslant 2$ weeks & 526 & $22.9 \pm 0.7$ & $20.0 \pm 0.5$ & $18.4 \pm 0.5$ \\
\hline \multirow[t]{2}{*}{$>2$ weeks } & 148 & $18.9 \pm 1.3$ & $17.1 \pm 1.0$ & $\mid 8.1 \pm 0.9$ \\
\hline & & $F_{(1,673)}=7.70, P=0.006$ & $F_{(1,673)}=6.94, P=0.008$ & $F_{(1,673)}=0.05, P=0.817$ \\
\hline \multicolumn{5}{|c|}{ Nicotine dependence ${ }^{\mathrm{b}}$} \\
\hline ND- & 270 & $21.3 \pm 0.9$ & $19.0 \pm 0.7$ & $18.0 \pm 0.7$ \\
\hline \multirow[t]{2}{*}{$\mathrm{ND}+$} & 404 & $22.5 \pm 0.8$ & $19.6 \pm 0.6$ & $18.5 \pm 0.5$ \\
\hline & & $F_{(1,673)}=0.97, P=0.324$ & $F_{(1,673)}=0.52, P=0.472$ & $F_{(1,673)}=0.23, P=0.629$ \\
\hline
\end{tabular}

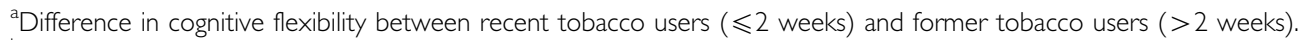

bifference in cognitive flexibility between subject with nicotine dependence (ND+) and without ND (ND-).

$\% \mathrm{PR}$, percentage of perseverative responses; \%PE, percentage of perseverative errors; \% $\mathrm{N}-\mathrm{PE}$, percentage of nonperseverative errors; $r$, correlation coefficient.

$P$ values that are in bold indicate statistical significance.

prefrontal cortex (PFC) and the hippocampus (likely to be the anatomic brain structures related to memory) have been implicated in cognition. A number of such genes have been identified, including the brain-derived neurotrophic factor gene (BDNF; Egan et al, 2003), the serotonin receptor 2A gene (5-HT2 $\alpha$; de Quervain et al, 2003), the catechol-O-methyltransferase gene (COMT; Caldu et al, 2007), the dopamine receptor D1 gene (DRD1; Rybakowski et al, 2005), the dopamine transporter gene (DAT; Caldu et al, 2007), the prion protein gene (PRNP; Papassotiropoulos et al, 2005), the Reelin gene (RELN; Wedenoja et al, 2008), and the kallikrein 8 gene (KLK8; Lu et al, 2009). Recently, two new genes (KIBRA and CLSTN2) were added to this group due to their impact on memory performance.

The aim of this study was to increase the specificity of the findings on the association of KIBRA and CLSTN2 with cognition. Different from other studies, we assessed cognitive function with the WCST. Three major findings were obtained. First, as observed in most previous studies, variation within KIBRA was associated with cognitive function, though we found evidence of a different mechanism of the effect. In the paper by Papassotiropoulos et al (2006), the KIBRA rs17070145 $\mathrm{T}$ allele was reported to have a beneficial effect on episodic memory performance. In contrast, in this study, the KIBRA rs17070145 T allele was associated with less cognitive flexibility (ie, significantly more perseverative responses and perseverative errors) in EAs (Table 5). A plausible explanation for the discrepancy in these results is that different aspects of cognition were assessed in the studies, which may reflect the function of different memory-related brain regions. Papassotiropoulos et al (2006) evaluated episodic memory of subjects using 5-min and 24-h delayed free recall performance, whereas in this study, multiple cognitive functions (problem solving, set shifting, working memory, and attention) of subjects were examined by the WCST. The working memory and set shifting (two major aspect of cognitive flexibility) are controlled mainly by the prefrontal cortex and they act jointly to enable the individual to adapt to a changing environment (Konishi et al, 1999). We hypothesize that the KIBRA rs17070145 $\mathrm{T}$ allele differentially modulates memory-related activities in the hippocampus (ie, where it has a beneficial effect on long-lasting memory) and the prefrontal cortex (ie, where it compromises short-term memory or working memory). Additionally, in this study, neither CLSTN2 SNP rs6439886 (in intron 1) nor CLSTN2 SNP rs17348572 (a nonsynonymous variant in exon 7) was found to be associated with significantly altered cognitive flexibility in AAs or EAs (Tables 4 and 5). These findings differ from those obtained by Papassotiropoulos et al (2006) and Jacobsen et al (2009). The inconsistent results may reflect different genetic effects of variation in CLSTN2 (and KIBRA) on different memory-related phenotypes (episodic 
Table 3 Influence of Nongenetic Factors on Cognitive Flexibility Measured by Wisconsin Card Sorting Tests in European Americans (EAs)

\begin{tabular}{|c|c|c|c|c|}
\hline & & \%PR & $\% \mathrm{PE}$ & $\%$ N-PE \\
\hline \multicolumn{5}{|c|}{ Effects of continuous nongenetic variables (correlation analyses) } \\
\hline \multirow[t]{2}{*}{ Age } & & $P<0.001$ & $P<0.001$ & $\mathbf{P}<\mathbf{0 . 0 0 I}$ \\
\hline & & $(r=0.200)$ & $(r=0.210)$ & $(r=0.190)$ \\
\hline \multirow[t]{3}{*}{ Education } & & $P=0.054$ & $P=0.056$ & $P=0.061$ \\
\hline & & $(r=-0.094)$ & $(r=-0.096)$ & $(r=-0.092)$ \\
\hline & & $($ mean \pm SEM) & $($ mean \pm SEM) & $($ mean \pm SEM) \\
\hline \multicolumn{5}{|c|}{ Effects of categorical nongenetic variables (multivariate GLM procedure) } \\
\hline \multicolumn{5}{|l|}{ Sex } \\
\hline Male & 248 & $16.4 \pm 0.8$ & $14.7 \pm 0.6$ & $|4| \pm 0.6$. \\
\hline \multirow[t]{2}{*}{$>2$ weeks } & 101 & $18.6 \pm 1.3$ & $16.0 \pm 1.0$ & $13.4 \pm 1.0$ \\
\hline & & $F_{(1,418)}=3.72, P=0.055$ & $F_{(1,418)}=2.26, P=0.133$ & $F_{(1,418)}=0.66, P=0.419$ \\
\hline \multicolumn{5}{|c|}{ Nicotine dependence ${ }^{b}$} \\
\hline ND- & 159 & $17.6 \pm 1.0$ & $15.5 \pm 0.8$ & $13.2 \pm 0.8$ \\
\hline \multirow[t]{2}{*}{$\mathrm{ND}+$} & 260 & $15.5 \pm 0.8$ & $14.0 \pm 0.6$ & $14.6 \pm 0.6$ \\
\hline & & $F_{(1,418)}=2.58, P=0.109$ & $F_{(1,418)}=2.16, P=0.143$ & $F_{(1,418)}=1.99, P=0.159$ \\
\hline
\end{tabular}

${ }^{a}$ Difference in cognitive flexibility between recent tobacco users ( $\leqslant 2$ weeks) and former tobacco users ( $>2$ weeks).

${ }^{b}$ Difference in cognitive flexibility between subject with nicotine dependence (ND+) and without ND (ND-).

\%PR, percentage of perseverative responses; \%PE, percentage of perseverative errors; \%N-PE, percentage of nonperseverative errors; $r$, correlation coefficient.

$P$ values that are in bold indicate statistical significance.

Table 4 Association of SNPs rs I7070I45 (KIBRA), rs6439886 (CLSTN2), and rs 17348572 (CLSTN2) with Cognitive Flexibility in African Americans (AAs)

\begin{tabular}{|c|c|c|c|c|}
\hline & $n$ & $\begin{array}{c}\% \mathrm{PR} \\
(\text { mean } \pm \text { SEM) }\end{array}$ & $\begin{array}{c}\% \mathrm{PE} \\
(\text { mean } \pm \text { SEM) }\end{array}$ & $\begin{array}{c}\% \text { N-PE } \\
\text { (mean } \pm \text { SEM) }\end{array}$ \\
\hline $\mathrm{CC}$ & 102 & $21.7 \pm 1.5$ & $19.4 \pm 1.2$ & $17.8 \pm 1.1$ \\
\hline$C T$ & 315 & $21.6 \pm 0.8$ & $18.9 \pm 1.6$ & $18.4 \pm 0.6$ \\
\hline TT & 251 & $22.4 \pm 1.0$ & $19.6 \pm 0.7$ & $18.4 \pm 0.7$ \\
\hline \multicolumn{5}{|c|}{ rs6439886 } \\
\hline $\mathrm{CC}$ & 96 & $23.2 \pm 1.5$ & $20.0 \pm 1.2$ & $17.3 \pm 1.1$ \\
\hline $\mathrm{CT}$ & 221 & $22.4 \pm 1.0$ & $19.6 \pm 0.8$ & $18.4 \pm 0.7$ \\
\hline \multirow[t]{2}{*}{ TT } & 350 & $21.3 \pm 0.8$ & $18.9 \pm 0.6$ & $18.6 \pm 0.6$ \\
\hline & & $F_{(2,666)}=0.71, P=0.492$ & $F_{(2,666)}=0.47, P=0.627$ & $F_{(2,666)}=0.55, P=0.578$ \\
\hline \multirow[t]{2}{*}{ TT } & 626 & $22.2 \pm 0.6$ & $19.5 \pm 0.5$ & $18.4 \pm 0.4$ \\
\hline & & $F_{(1,654)}=0.68, P=0.410$ & $F_{(1,654)}=0.80, P=0.372$ & $F_{(1,654)}=0.00, P=0.997$ \\
\hline
\end{tabular}

${ }^{\mathrm{a}}$ Only one subject had CLSTN2 17348572 CC genotype.

$\% \mathrm{PR}$, percentage of perseverative responses; \% $\mathrm{PE}$, percentage of perseverative errors; \% $\mathrm{N}$-PE, percentage of nonperseverative errors.

Neuropsychopharmacology 
Table 5 Association of SNPs rs 17070 I 45 (KIBRA), rs6439886 (CLSTN2) and rs 17348572 (CLSTN2) with Cognitive Flexibility in European Americans (EAs)

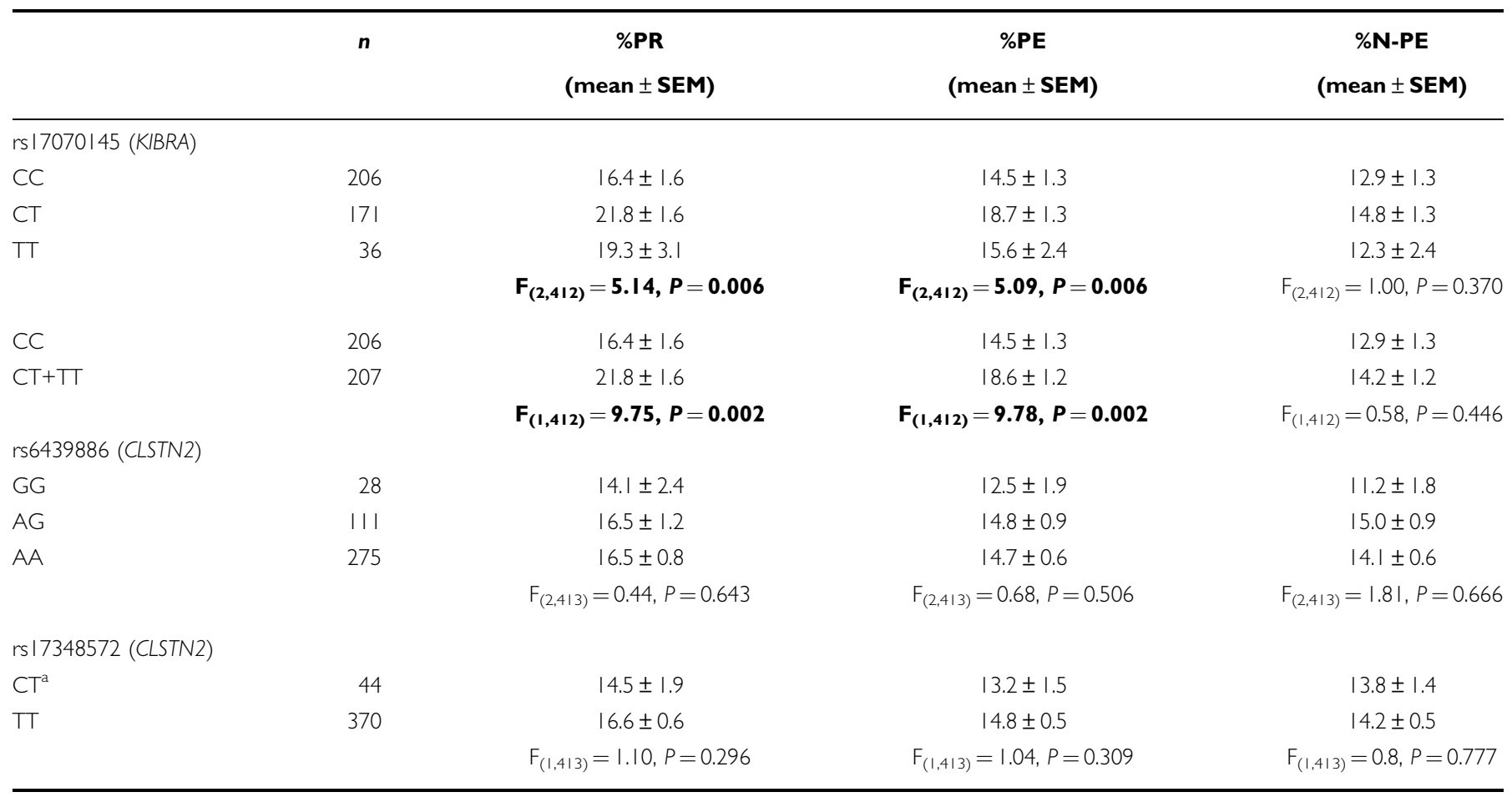

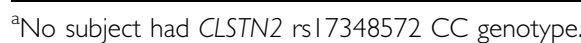

$\% \mathrm{PR}$, percentage of perseverative responses; \%PE, percentage of perseverative errors; \%N-PE, percentage of nonperseverative errors.

$P$ values that are in bold indicate statistical significance.

memory performance measured in the previous studies and working memory performance measured in this study). In addition, the discrepancies may be due to different smoking status of the study participants included in previous and current studies (given the high prevalence rate of smoking in the general population). Genotype $\times$ tobacco exposure (or withdrawal) interactions can exert a striking role in cognitive performance (Loughead et al, 2008). This study, in contrast to the previous one, took into consideration the interactive effect of smoking and genetics on cognitive flexibility. Therefore, it is not unusual to obtain these different results.

Second, the genetic effect of KIBRA on cognitive flexibility was population specific. As shown in Tables 4 and 5, the KIBRA (rs17070145) T allele appeared to be a risk factor for cognitive flexibility in EAs. However, this allele did not show a noticeable effect on cognitive flexibility in AAs. As this SNP is located in intron 9 of KIBRA, it is unlikely that it represents a causal variant with a substantial effect on cognitive flexibility. Possibly, SNP rs17070145 is in close linkage disequilibrium (LD) with a functional variant that can change the expression level of KIBRA, leading to altered cognitive flexibility. However, as LD between SNP rs17070145 and other potentially functional variants in KIBRA may vary by population, the genetic effect of SNP rs17070145 may be evident in one population but not another. In addition, the allele frequency of the $\mathrm{T}$ allele of SNP 17070145 was significantly higher in AAs $(\sim 61 \%)$ than in EAs $(\sim 29 \%)$. The significant difference in KIBRA (rs17070145) $\mathrm{T}$ allele frequency is consistent with a population-specific effect of KIBRA variants.
Third, the influence of recent smoking on cognitive flexibility was population specific, and recent smoking appeared to offset the genetic effect of the deleterious KIBRA variant on cognitive flexibility in EAs. When both AAs and EAs were examined jointly (irrespective of genotype information), no difference in cognitive flexibility was seen between current tobacco users (tobacco use $\leqslant 2$ weeks) and past tobacco users (tobacco use $>2$ weeks; data not shown). However, we found a population-specific effect of recent smoking on cognitive flexibility when we examined AAs and EAs separately. Although recent smoking was associated with significantly less cognitive flexibility (ie, more perseverative responses and perseverative errors) in AAs (Table 2), it was associated with greater cognitive flexibility (ie, fewer perseverative responses and perseverative errors) in EAs (Table 3). This result may partially explain the findings by Vega and Gil (2005) of an ethnic/racial difference in rates and progress of tobacco use. In a 10-year study, these investigators found that AAs were less likely than EAs and Latinos to begin smoking in early adolescence and were least likely to be smokers as young adults, whereas EAs were most likely to still be smoking at 20 years of age. This is consistent with a negative effect of smoking on cognitive flexibility in AAs that may deter AAs from smoking, but a positive effect of smoking on cognitive flexibility in EAs may attract and sustain EA smokers. An interactive effect of variation in KIBRA and tobacco recency on cognitive flexibility was observed in EAs only. Although those EA subjects with the KIBRA (rs17070145) T allele had significantly less cognitive flexibility (ie, more perseverative responses and perseverative errors) than EAs without the $\mathrm{T}$ 
a $\square$ KIBRA_rs17070145_CT+TT_Tobacco recency $\leq 2$ weeks $(n=159)$ $\square$ KIBRA_rs17070145_CT+T_Tobacco recency $>2$ weeks $(n=48)$

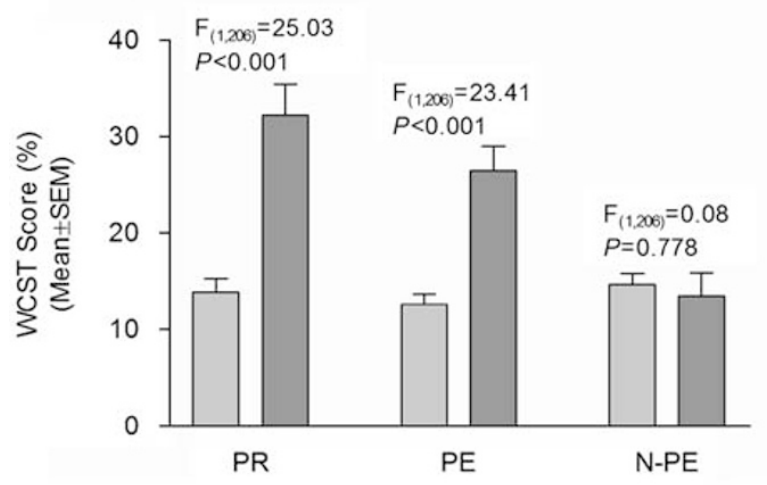

b

$\square$ KIBRA_rs17070145_CC_Tobacco recency $\leq 2$ weeks $(n=153)$

$\square$ KIBRA_rs17070145_CC_Tobacco recency $>2$ weeks $(n=53)$

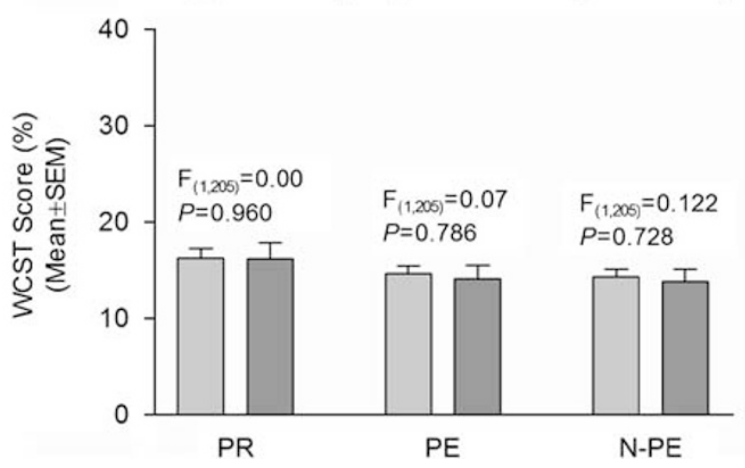

Figure I Interactive effects of KIBRA SNP rs/7070I45 and tobacco recency on cognitive flexibility in European Americans (EAs). (a) Interactive effects of rs 17070145 genotypes $C T+\Pi$ and tobacco recency on cognitive flexibility. (b) Interactive effects of rs I 7070 I 45 genotype CC and tobacco recency on cognitive flexibility. WCST Score (\%) (mean \pm SEM): Wisconsin Cart Sorting Test Score (\%) (mean \pm SEM) obtained by the general linear model (GLM) multivariate analysis of variance; \%PR: percentage of perseverative responses; \%PE: percentage of perseverative errors; \%N-PE: percentage of nonperseverative errors.

allele (Table 5), current smokers failed to show this detrimental effect (Figure 1). This finding implies that nicotine can improve cognitive flexibility (eg, attention, working memory, and set shifting) in EA subjects whose cognitive performance is diminished by certain risk gene variants such as the KIBRA (rs17070145) T allele.

Additionally, this study indicated that cognitive flexibility was not only moderated by specific genetic factors, but also by nongenetic factors. One nongenetic factor was age, an effect that is well known. Another nongenetic factor was education. More education is correlated with better decision making, problem solving, and a higher general cognitive function. Therefore, when analyzing genetic effects on cognitive flexibility, the confounding effect of nongenetic factors such as age and education cannot be ignored. This study has several strengths. First, to our knowledge, it is the largest study to examine the effect of genes on specific aspects of cognitive function. Second, the WCST is the most frequently used measure of cognitive flexibility. It is a complex test that draws on various components of executive function. The use of three major domains (perseverative responses, perseverative errors, and nonperseverative errors) of the WCST provides a measure of different aspects of cognitive flexibility. An increase in the number of perseverative errors (resulting from a poor working memory) has been associated with frontal lobe dysfunction (Monchi et al, 2001). Moreover, a relatively greater increase in perseverative versus nonperseverative errors may occur either when impairments in working memory are severe or cognitive inflexibility is present (Hartman et al, 2003). Third, we used the percentage of WCST responses or errors to assess cognitive flexibility, rather than the absolute number of WCST responses or errors. The percentage of WCST responses or errors may more accurately reflect the difference in cognitive flexibility among individual subjects (Rybakowski et al, 2005).

The major drawback of this study was that only one variant in KIBRA and two variants in CLSTN2 were analyzed for their association with cognitive flexibility. This decision was based on our wish to extend previous observations and avoid excessive multiple testing. Both KIBRA and CLSTN2 are large genes. KIBRA, which is about $180 \mathrm{~kb}$ long, has 23 exons, and CLSTN2, which is about $630 \mathrm{~kb}$, has 17 exons. SNPs in KIBRA or CLSTN2 are not in substantial LD; KIBRA SNP rs17070145 (or CLSTN2 SNPs rs6439886 and rs17348572) cannot fully capture the genetic information of other SNPs in KIBRA (or CLSTN2). Need et al (2008) identified a KIBRA SNP that was weakly associated with delayed recall in the Auditory Verbal Learning Test (AVLT) task $(P=0.03)$ but not in LD with SNP rs17070145. Thus, increasing the density of markers in KIBRA or CLSTN2 could increase the chance of identifying one or more loci that affect cognitive flexibility, but only findings with very high statistical significance would survive Bonferroni correction, ie, there would be a marked reduction in power. Another weakness of this study is that there were no data available for current exposure to nicotine on the day of testing. Thus, it is not known whether immediate nicotine exposure has a stronger effect on cognition than past nicotine exposure (within 2 weeks). Additionally, current smokers under abstinence may experience nicotine withdrawal, leading to deleterious effect on cognitive performance. However, this problem was not tackled in this study.

In summary, this work supports an association of a KIBRA variant with cognitive flexibility, though differently than previously reported and in a population-specific manner. To understand completely the potential role of KIBRA or CLSTN2 variants in cognitive flexibility, additional genetic association studies using a fine mapping strategy are warranted.

\section{ACKNOWLEDGEMENTS}

This work was supported, in part, by funds from the National Institute on Drug Abuse (R01 DA12849, R01 DA12690, K24 DA15105, K24 DA022288, and K99DA022891), the National Institute on Alcohol Abuse and Alcoholism (R01AA11330, P50 AA12870, K08 AA13732, and K24 AA13736), and the National Center for Research Resources (M01 RR06192; University of Connecticut General Clinical Research Center); and the US Department of Veterans Affairs (The National Center for PTSD Research, 
the VA Medical Research Program and the VA ConnecticutMassachusetts Mental Illness Research, Education and Clinical Center (MIRECC), the VA Research Enhancement Award Program (REAP), and the MERIT Program). It was also partially supported by the Alcoholic Beverage Medical Research Foundation (ABMRF) grant (H Zhang) and the National Institute of Neurological Disorders and Stroker grant R01NS043530 (JR Gruen). AnnMarie Lacobelle (The VA Connecticut Healthcare Systems, West Haven, CT, USA) provided excellent technical assistance. Yari Nunez (APT Foundation, New Haven, CT, USA) and Jessica Bona (The University of Connecticut Health Center, Farmington, CT, USA) assisted in WCST data collection. Critical database management services were provided by John Farrell. We thank the individuals who volunteered to participate in this study and the expert interviewers who phenotyped the participants.

\section{DISCLOSURE/CONFLICTS OF INTEREST}

Dr Kranzler has received consulting fees from OrthoMcNeil Pharmaceuticals (Raritan, NJ), H Lundbeck A/S (Copenhagen, Denmark), Forest Pharmaceuticals (St Louis, MO), elbion NV (Leuven, Belgium), Sanofi-Aventis (Bridgewater, NJ), Solvay Pharmaceuticals (Brussels, Belgium), and Alkermes Inc. (Cambridge, MA). He has received research support from Ortho-McNeil Pharmaceuticals and BristolMyers Squibb Company (New York, NY), and honoraria from Forest Pharmaceuticals and Alkermes Inc. Other authors have no conflict of interest to report.

\section{REFERENCES}

Almeida OP, Schwab SG, Lautenschlager NT, Morar B, Greenop KR, Flicker L et al (2008). KIBRA genetic polymorphism influences episodic memory in later life, but does not increase the risk of mild cognitive impairment. J Cell Mol Med 12: $1672-1676$.

American Psychiatric Association (1994). Diagnostic and Statistical Manual of Mental Disorders, 4th edn. Author: Washington, DC.

Ando J, Ono Y, Wright MJ (2001). Genetic structure of spatial and verbal working memory. Behav Genet 31: 615-624.

Buther K, Plaas C, Barnekow A, Kremerskothen J (2004). KIBRA is a novel substrate for protein kinase Czeta. Biochem Biophys Res Commun 317: 703-707.

Caldu X, Vendrell P, Bartres-Faz D, Clemente I, Bargallo N, Jurado MA et al (2007). Impact of the COMT Val108/158 Met and DAT genotypes on prefrontal function in healthy subjects. Neuroimage 37: 1437-1444.

Canas J, Quesada JF, Antoli A, Fajardo I (2003). Cognitive flexibility and adaptability to environmental changes in dynamic complex problem-solving tasks. Ergonomics 46: 482-501.

Chen LS, Rice TK, Thompson PA, Barch DM, Csernansky JG (2009). Familial aggregation of clinical and neurocognitive features in sibling pairs with and without schizophrenia. Schizophr Res 111: 159-166.

Corneveaux JJ, Liang WS, Reiman EM, Webster JA, Myers AJ, Zismann VL et al (2008). Evidence for an association between KIBRA and late-onset Alzheimer's disease. Neurobiol Aging (e-pub ahead of print).

de Quervain DJ, Henke K, Aerni A, Coluccia D, Wollmer MA, Hock C et al (2003). A functional genetic variation of the 5-HT2a receptor affects human memory. Nat Neurosci 6: 1141-1142.
Egan MF, Kojima M, Callicott JH, Goldberg TE, Kolachana BS, Bertolino A et al (2003). The BDNF val66met polymorphism affects activity-dependent secretion of BDNF and human memory and hippocampal function. Cell 112: 257-269.

Ernst M, Heishman SJ, Spurgeon L, London ED (2001). Smoking history and nicotine effects on cognitive performance. Neuropsychopharmacology 25: 313-319.

Greve KW, Stickle TR, Love JM, Bianchini KJ, Stanford MS (2005). Latent structure of the Wisconsin Card Sorting Test: a confirmatory factor analytic study. Arch Clin Neuropsychol 20: 355-364.

Hartman M, Steketee MC, Silva S, Lanning K, Andersson C (2003). Wisconsin Card Sorting Test performance in schizophrenia: the role of working memory. Schizophr Res 63: 201-217.

Heaton RK, PAR Staff (1999). Wisconsin Card Sorting Test (Computer Version 3 for Windows Research Edition). Psychological Assessment Resources: Odessa, FL.

Hintsch G, Zurlinden A, Meskenaite V, Steuble M, Fink-Widmer K, Kinter J et al (2002). The calsyntenins-a family of postsynaptic membrane proteins with distinct neuronal expression patterns. Mol Cell Neurosci 21: 393-409.

Jacobsen LK, Krystal JH, Mencl WE, Westerveld M, Frost SJ, Pugh KR (2005). Effects of smoking and smoking abstinence on cognition in adolescent tobacco smokers. Biol Psychiatry 57: $56-66$.

Jacobsen LK, Picciotto MR, Heath CJ, Mencl WE, Gelernter J (2009). Allelic variation of calsyntenin 2 (CLSTN2) modulates the impact of developmental tobacco smoke exposure on mnemonic processing in adolescents. Biol Psychiatry 65: 671-679.

Johannsen S, Duning K, Pavenstadt H, Kremerskothen J, Boeckers TM (2008). Temporal-spatial expression and novel biochemical properties of the memory-related protein KIBRA. Neuroscience 155: 1165-1173.

Johansson B, Whitfield K, Pedersen NL, Hofer SM, Ahern F, McClearn GE (1999). Origins of individual differences in episodic memory in the oldest-old: a population-based study of identical and same-sex fraternal twins aged 80 and older. J Gerontol B Psychol Sci Soc Sci 54: 173-179.

Konishi S, Kawazu M, Uchida I, Kikyo H, Asakura I, Miyashita Y (1999). Contribution of working memory to transient activation in human inferior prefrontal cortex during performance of the Wisconsin Card Sorting Test. Cereb Cortex 9: 745-753.

Kremerskothen J, Plaas C, Buther K, Finger I, Veltel S, Matanis T et al (2003). Characterization of KIBRA, a novel WW domaincontaining protein. Biochem Biophys Res Commun 300: 862-867.

Loughead J, Wileyto EP, Valdez JN, Sanborn P, Tang K, Strasser AA et al (2008). Effect of abstinence challenge on brain function and cognition in smokers differs by COMT genotype. Mol Psychiatry (e-pub ahead of print).

Lu ZX, Huang Q, Su B (2009). Functional characterization of the human-specific (type II) form of kallikrein 8, a gene involved in learning and memory. Cell 19: 259-267.

Maggio R, Riva M, Vaglini F, Fornai F, Molteni R, Armogida M et al (1998). Nicotine prevents experimental parkinsonism in rodents and induces striatal increase of neurotrophic factors. J Neurochem 71: 2439-2446.

McClearn GE, Johansson B, Berg S, Pedersen NL, Ahern F, Petrill SA et al (1997). Substantial genetic influence on cognitive abilities in twins 80 or more years old. Science 276: 1560-1563.

Monchi O, Petrides M, Petre V, Worsley K, Dagher A (2001). Wisconsin Card Sorting revisited: distinct neural circuits participating in different stages of the task identified by eventrelated functional magnetic resonance imaging. J Neurosci 21: 7733-7741.

Nacmias B, Bessi V, Bagnoli S, Tedde A, Cellini E, Piccini C et al (2008). KIBRA gene variants are associated with episodic 
memory performance in subjective memory complaints. $\mathrm{Neu}$ rosci Lett 436: 145-147.

Need AC, Attix DK, McEvoy JM, Cirulli ET, Linney KN, Wagoner AP et al (2008). Failure to replicate effect of Kibra on human memory in two large cohorts of European origin. Am $J$ Med Genet B Neuropsychiatr Genet 147B: 667-668.

Papassotiropoulos A, Stephan DA, Huentelman MJ, Hoerndli FJ, Craig DW, Pearson JV et al (2006). Common Kibra alleles are associated with human memory performance. Science 314: $475-478$.

Papassotiropoulos A, Wollmer MA, Aguzzi A, Hock C, Nitsch RM, de Quervain DJ (2005). The prion gene is associated with human long-term memory. Hum Mol Genet 14: 2241-2246.

Pastalkova E, Serrano P, Pinkhasova D, Wallace E, Fenton AA, Sacktor TC (2006). Storage of spatial information by the maintenance mechanism of LTP. Science 313: 1141-1144.

Pierucci-Lagha A, Gelernter J, Chan G, Arias A, Cubells JF, Farrer L et al (2007). Reliability of DSM-IV diagnostic criteria using the semi-structured assessment for drug dependence and alcoholism (SSADDA). Drug Alcohol Depend 91: 85-90.

Pierucci-Lagha A, Gelernter J, Feinn R, Cubells JF, Pearson D, Pollastri A et al (2005). Diagnostic reliability of the Semistructured Assessment for Drug Dependence and Alcoholism (SSADDA). Drug Alcohol Depend 80: 303-312.

Polderman TJ, Gosso MF, Posthuma D, Van Beijsterveldt TC, Heutink P, Verhulst FC et al (2006). A longitudinal twin study on IQ, executive functioning, and attention problems during childhood and early adolescence. Acta Neurol Belg 106: 191-207.

Robinson AL, Heaton RK, Lehman RA, Stilson DW (1980). The utility of the Wisconsin Card Sorting Test in detecting and localizing frontal lobe lesions. J Consult Clin Psychol 48: 605-614.

Rodriguez-Rodriguez E, Infante J, Llorca J, Mateo I, SanchezQuintana C, Garcia-Gorostiaga I et al (2009). Age-dependent association of KIBRA genetic variation and Alzheimer's disease risk. Neurobiol Aging 30: 322-324.

Rybakowski JK, Borkowska A, Czerski PM, Kapelski P, DmitrzakWeglarz M, Hauser J (2005). An association study of dopamine receptors polymorphisms and the Wisconsin Card Sorting Test in schizophrenia. J Neural Transm 112: 1575-1582.

Schaper K, Kolsch H, Popp J, Wagner M, Jessen F (2008). KIBRA gene variants are associated with episodic memory in healthy elderly. Neurobiol Aging 29: 1123-1125.

Shema R, Sacktor TC, Dudai Y (2007). Rapid erasure of long-term memory associations in the cortex by an inhibitor of PKM zeta. Science 317: 951-953.

Shi MM, Myrand SP, Bleavins MR, de 1 I (1999). High throughput genotyping for the detection of a single nucleotide polymorphism in $\mathrm{NAD}(\mathrm{P}) \mathrm{H}$ quinone oxidoreductase (DT diaphorase) using TaqMan probes. Mol Pathol 52: 295-299.

Taylor J (2007). Heritability of Wisconsin Card Sorting Test (WCST) and Stroop Color-Word Test performance in normal individuals: implications for the search for endophenotypes. Twin Res Hum Genet 10: 829-834.

Uhl GR, Liu QR, Drgon T, Johnson C, Walther D, Rose JE et al (2008). Molecular genetics of successful smoking cessation: convergent genome-wide association study results. Arch Gen Psychiatry 65: 683-693.

Vega WA, Gil AG (2005). Revisiting drug progression: long-range effects of early tobacco use. Addiction 100: 1358-1369.

Wedenoja J, Loukola A, Tuulio-Henriksson A, Paunio T, Ekelund J, Silander K et al (2008). Replication of linkage on chromosome 7q22 and association of the regional Reelin gene with working memory in schizophrenia families. Mol Psychiatry 13: 673-684.

Wright M, De Geus E, Ando J, Luciano M, Posthuma D, Ono Y et al (2001). Genetics of cognition: outline of a collaborative twin study. Twin Res 4: 48-56.

Yoshihama Y, Hirai T, Ohtsuka T, Chida K (2009). KIBRA Colocalizes with protein kinase Mzeta (PKMzeta) in the mouse hippocampus. Biosci Biotechnol Biochem 73: 147-151.

Zhang H, Kranzler HR, Weiss RD, Luo X, Brady KT, Anton RF et al (2009). Pro-opiomelanocortin gene variation related to alcohol or drug dependence: evidence and replications across familyand population-based studies. Biol Psychiatry 66: 128-136. 